\title{
Serum selenium concentration related to myocardial infarction and fatty acid content of serum lipids
}

\author{
TATU A MIETTINEN, GEORG ALFTHAN JUSSI K HUTTUNEN, JARMO PIKKARAINEN, \\ VESA NAUKKARINEN, SEPPO MATTILA, TORGER KUMLIN
}

\begin{abstract}
A longitudinal case-control study of 33 patients with one or more risk factors for coronary heart disease and 64 controls showed that the serum selenium concentration (range 0.63-1.33 $\mu \mathrm{mol} / 1$ (50-105 $\mu \mathrm{g} / 1)$ ) was not associated with development of clinical manifestations of coronary heart disease during a follow up of five to seven years. The content of polyunsaturated fatty acids, especially eicosapentaenoic acid, in serum cholesterol esters and phospholipids was positively correlated with selenium concentration.

As a low content of polyunsaturated fatty acids in serum lipids was an independent risk factor for coronary heart disease in these subjects it may be hypothesised that the high coronary risk in subjects with a very low serum selenium concentration $(<0.57 \mu \mathrm{mol} / 1(<45 \mu \mathrm{g} / \mathrm{l}))$ might be due not to selenium deficiency but to the coexisting low concentrations of polyunsaturated fatty acids in serum.
\end{abstract}

\footnotetext{
Second Department of Medicine, University of Helsinki, 00290 Helsinki 29, Finland

TATU A MIETTINEN, MD, professor of medicine
}

National Public Health Institute, 00280 Helsinki 28, Finland GEORG ALFTHAN, MSC, research associate JUSSI K HUTTUNEN, MD, professor and director JARMO PIKKARAINEN, MD, professor

Jorvi Hospital, Espoo, Finland

VESA NAUKKARINEN, MD, senior physician

Pension Insurance Company Kalervo, Helsinki, Finland SEPPC MATTILA, MD, senior physician

Finnair Co, Helsinki, Finland

TORGER KUMLIN, MD, senior physician

Correspondence to: $\mathrm{Dr} \mathrm{T}$ A Miettinen.

\section{Introduction}

Recent prospective studies have indicated that a very low serum selenium concentration $(<0.57 \mu \mathrm{mol} / 1(<45 \mu \mathrm{g} / \mathrm{l})$ ) is associated with increased clinical manifestation of coronary heart disease. ${ }^{1}$ In another study a relatively low content of polyunsaturated fatty acids in serum phospholipids was shown to be an independent risk factor for coronary heart disease. ${ }^{2}$ We studied in the same subjects the relation of the serum selenium concentration to the risk of future coronary heart disease and to the concurrent distribution of serum fatty acids.

\section{Patients and methods}

Serum samples for measurement of selenium concentrations were obtained in 1974-5 from 1222 middle aged men at the beginning of our multifactorial prevention study aimed at preventing coronary heart disease. All these men had one or more of the following risk factors for coronary heart disease ${ }^{2-3}$ : hypertension, hyperlipidaemia, smoking, overweight, or abnormal glucose tolerance. About $85 \%$ of the men were living in south western Finland, and most belonged to the upper social class. ${ }^{3}$ During the subsequent five to seven years 33 of the men died suddenly or experienced fatal or non-fatal myocardial infarction verified by typical chest pain, raised enzyme concentrations, and electrocardiographic changes or by the appearance of a $Q$ wave on an electrocardiogram. For these 33 men 64 controls without disease were selected from the remaining 1189 subjects. The coronary events had mainly accumulated in subjects with initial hyperlipidaemia, those with hypertension, and those who smoked. ${ }^{2}$ Therefore, as described previously, ${ }^{2}$ the controls were randomly selected from among the men without disease so that the group of cases and the control group were matched for age (mean (SE) 48 (1) years in cases $v 48$ (1; years in controls); systolic (154 (3) $v 156$ (4) $\mathrm{mm} \mathrm{Hg}$ ) and diastolic (100 (2) $v 101$ (1) $\mathrm{mm} \mathrm{Hg}$ ) blood pressures; serum cholesterol concentration $(7 \cdot 6(0 \cdot 2) v 7 \cdot 4(0 \cdot 1) \mathrm{mmol} / \mathrm{l}(294(8) v 286(4) \mathrm{mg} /$ $100 \mathrm{ml})$ ); triglyceride concentration $(2 \cdot 0(0 \cdot 2) v 1.9(0 \cdot 1) \mathrm{mmol} / \mathrm{l}(177$ $(18 v 168(9) \mathrm{mg} / 100 \mathrm{ml})$ ); smoking (14 non-smokers $(42 \%) v 28$ $(44 \%)$; obesity (relative body weight $115(2) v 116(2) \%)$; and oral glucose tolerance (one hour blood glucose concentration $7.3(0.4) v$ $7 \cdot 6(0.3) \mathrm{mmol} / 1(132(7) v 137(5) \mathrm{mg} / 10 \mathrm{C} \mathrm{ml}))$ at the start of the follow up.

As fasting serum samples had been obtained at entry to the study and stored frozen throughout the follow up period at $-20^{\circ} \mathrm{C}$ the 
initial serum selenium concentration could be measured in the two groups. The fatty acid composition of those samples has been reported previously. ${ }^{2}$ Serum selenium concentrations were measured by graphite furnace atomic absorption spectrometry after a simple dilution procedure as described earlier. ${ }^{4}$ The method of measuring the fatty acid composition of serum lipids in the 97 men has been reported previously. ${ }^{2}$

\section{Results}

The mean (SE) serum selenium concentration at the start of the study was $0.91(0.03) \mu \mathrm{mol} / 1(71.6(2.4) \mu \mathrm{g} / \mathrm{l})$ in the patients with infarction $0.95(0.04) \mu \mathrm{mol} / 1(75.2(3.3) \mu \mathrm{g} / \mathrm{l})$ in fatal cases and $0.9(0.04)$ $\mu \mathrm{mol} / 1(70.8(2.9) \mu \mathrm{g} / \mathrm{l})$ in non-fatal cases and similar $(0.92(0.02) \mu \mathrm{mol} / 1$ $(72.9(1 \cdot 8) \mu \mathrm{g} / \mathrm{l}))$ in the controls. The figure shows that the distribution of patients with infarction and controls was similar at all selenium concentrations, indicating that a serum selenium concentration of 0.63 to $1.33 \mu \mathrm{mol} / \mathrm{l}(50$ to $105 \mu \mathrm{g} / \mathrm{l}$ ) is not a significant risk factor for coronary heart disease.

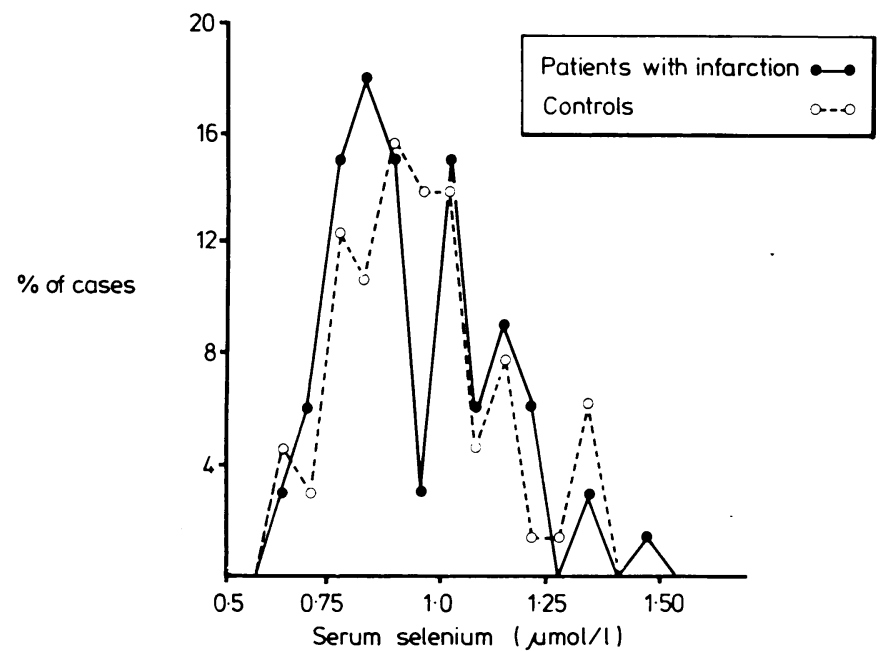

Distribution of serum selenium concentration in patients sustaining coronary events and controls.

Conversion: SI to traditional units-Selenium: $1 \mu \mathrm{mol} / 1 \approx 79 \mu \mathrm{g} / 1$.

No correlation could be observed between the serum selenium concentration and blood pressure, obesity, smoking, serum triglyceride or cholesterol concentration, and glucose tolerance. A plot of the serum selenium concentrations against the fatty acid contents in serum cholesterol esters and phospholipids (table) showed a poor correlation for linoleic acid $(18: 2)$. The correlation was consistently significant for 20:5 (eicosapentaenoic acid). Less consistent correlations were seen for $16: 0,20: 4$, and the sum of polyunsaturated fatty acids.

\section{Discussion}

In this longitudinal study, in contrast to the findings of Salonen et al, ${ }^{1}$ a low serum selenium concentration did not predict the development of future coronary heart disease. The results of the two investigations are not, however, conflicting as Salonen et al indicated that the risk associated with serum selenium concentration was confined to values below $0.57 \mu \mathrm{mol} / 1$ $(45 \mu \mathrm{g} / \mathrm{l})$, and this concentration was exceeded in all the subjects in the present study.

The different mean serum selenium concentrations in the two study groups are more difficult to explain. The average dietary intakes of selenium in 1972 and 1974-5 (the times of the initial examination in the two studies) have been reported to be similar. ${ }^{5}$ It should be noted, however, that the subjects reported on in this paper were from south western Finland and mostly belonged to the upper social class. ${ }^{3}$ In contrast, the
Correlation of serum selenium concentration with some fatty acids of serum lipids

\begin{tabular}{ccc}
\hline Fatty acid & $\begin{array}{c}\text { Controls } \\
(\mathrm{n}=64)\end{array}$ & $\begin{array}{c}\text { Patients with infarction } \\
(\mathrm{n}=33)\end{array}$ \\
\hline & Cholesterol esters & \\
$16: 0$ & $0.354^{* *}$ & $0.419^{*}$ \\
$18: 1$ & -0.097 & 0.267 \\
$18: 2$ & 0.029 & $-0.346^{*}$ \\
$20: 4$ & $0.490^{* * *}$ & 0.222 \\
$20: 5$ & $0.393^{* *}$ & $0.500^{* *}$ \\
PUFA & $0.495^{* * *}$ & 0.301 \\
& Phospholipids & \\
$16: 0$ & $0.414^{* * *}$ & 0.178 \\
$18: 1$ & -0.123 & 0.334 \\
$18: 2$ & -0.219 & -0.317 \\
$20: 4$ & $0.392^{* *}$ & 0.031 \\
$20: 5$ & $0.411^{* * *}$ & $0.436^{*}$ \\
PUFA & $0.488^{* * *}$ & 0.130 \\
& &
\end{tabular}

PUFA = Sum of polyunsaturated fatty acids with retention times longer than that of $18: 3$ in gas liquid chromatography, ${ }^{2}$ including $20: 3(1) 9,20: 3 \omega 6,20: 4(1) 6,20: 5 \omega 3$, $22: 5 \omega 3$, and $22: 6 \omega 3$, expressed as percentage of total fatty acids up to $18: 3$.

${ }^{*} \mathrm{p}<0.05,{ }^{* *} \mathrm{p}<0.01, * * * \mathrm{p}<0.001$.

subjects in the study of Salonen et al belonged to a random population sample from eastern Finland.' At that time (1972-5) the dietary selenium intake was fairly low in Finland because consumption of domestic grain with a low selenium content was high and consumption of foreign imported cereal grain with a high selenium content was low. The most important dietary source of selenium in Finland in the early 1970s was fish, ${ }^{5-6}$ and the relatively high intake of fish in south western Finland may explain the relatively high selenium concentration in the present study.

The highly significant and consistent positive relation between the serum selenium concentration and the eicosapentaenoic acid content of cholesterol esters and phospholipids seen in this study might theoretically be due to direct effects of selenium or selenium dependent glutathione peroxidase on the fatty acid and prostaglandin metabolism. ${ }^{78} \mathrm{~A}$ second and perhaps more plausible explanation for the observed association is the distribution of selenium and eicosapentaenoic acid in the diet. It is possible that serum concentrations of selenium and eicosapentaenoate, a fatty acid peculiar to fish meat, both reflect the intake of fish at the time of blood sampling.

The strong association between the selenium concentration and the content of eicosapentaenoic acid suggests that the role of the low serum selenium concentration as an independent risk factor of coronary heart disease should be re-evaluated. Thus the risk associated with the extremely low serum selenium concentrations in the study of Salonen et al may be due not to selenium deficiency but to the coexisting low serum content of polyunsaturated fatty acids, like eicosapentaenoate. Patients with coronary heart disease and atherosclerosis in general appear to have a low linoleic acid content in plasma cholesterol esters, ${ }^{9-12}$ and an association between the serum concentration of polyunsaturated fatty acids and coronary heart disease has been reported recently in a prospective case-control study carried out in the subjects in the present investigation. ${ }^{2}$

This study was supported by the Finnish National Council for Medical Research.

\section{References}

1 Salonen JT, Alfthan G, Huttunen JK, Pikkarainen J, Puska P. Association between cardiovascular death and myocardial infarction in a matchedpair longitudinal study, Lancet 1982 ;ii:175-9.

${ }^{2}$ Miettinen TA, Naukkarinen V, Huttunen JK, Mattila S, Kumlin T. Fatty-acid composition of serum lipids predicts myocardial infarction. Br Med f 1982;285:993-6.

${ }^{3}$ Naukkarinen V. The feasibility of administering preventive treatment for coronary heart disease to middle-aged men. Helsinki: University of Helsinki, 1982. (MD thesis.)

- Alfthan G, Kumpulainen J. Determination of selenium in small volumes of blood plasma and serum in graphite furnace atomic absorption spectrometry. Analytica Chimica Acta 1982;140:221-7.

${ }^{5}$ Mutanen M, Koivistoinen P. The role of imported grain on the selenium 
intake of Finnish population 1941-1981. Int f Vitam Nutr Res 1983;53: 34-8.

${ }^{6}$ Varo P, Koivistoinen P. Mineral element composition of Finnish foods. XII. General discussion and nutritional evaluation. Acta Agriculturae Scandinavica 1980;suppl 22:165-71.

${ }^{7}$ Bryant RW, Bailey JM. Altered lipooxygenase metabolism and decreased glutathione peroxidase activity in platelets from selenium-deficient rats. Biochem Biophys Res Commun 1980;92:268-76.

${ }^{8}$ Levander OA. Selenium: biochemical actions, interactions, and some human health implications. In: Prasad AS, ed. Clinical, biochemical, and nutritional aspects of trace elements. New York: Alan R Liss, 1982: 345-68.
${ }^{9}$ Lewis B. Composition of plasma cholesterol ester in relation to coronaryartery disease and dietary fat. Lancet 1958;ii:71-3.

${ }^{10}$ Kirkeby K, Ingvaldsen P, Bjerkedal I. Fatty acid composition of serum lipids in men with myocardial infarction. Acta Med Scand 1972;192: 513-9.

11 Kingsbury KJ, Morgan DM, Stovold R, Brett GG, Anderson J. Polyunsaturated fatty acids and myocardial infarction. Lancet 1969 ;ii:1325-9.

12 Simpson HCR, Barker K, Carter RD, Cassels E, Mann JI. Low dietary intake of linoleic acid predisposes to myocardial infarction. $\mathrm{Br} \mathrm{Med} \mathcal{F}$ $1982 ; 285$ : $683-4$.

(Accepted 1 fune 1983)

\title{
Usefulness of apheresis to extract microfilarias in management of loiasis
}

\author{
LUDO MUYLLE, HENRI TAELMAN, ROBERT MOLDENHAUER, ROGER VAN BRABANT, \\ MARC E PEETERMANS
}

\begin{abstract}
Two patients with loiasis in whom treatment with diethylcarbamazine had tc be interrupted because of serious side effects underwent apheresis to extract microfilarias from the blood. After three apheresis sessions the number of microfilarias in the blooc had dropped from 8980 to $3412 / \mathrm{m}^{3}$ in one patient anc from 2950 to $1840 / \mathrm{m}^{2}$ in the other. Between 40 and $45 \times 10^{\circ}$ microfilarias: were removed from each of the patients. After reduction of the parasitaemia the two patients were given diethylcarbamazine; no appreciable side effects occurred, and the patients were cured.
\end{abstract}

\section{Introduction}

Loiasis is a parasitic infection caused by Loa loa filarias, anc' is most prevalent in the rain forest belt of western and centra: Africa. The infection has a prevalence of almost $100 \%$ in some places and is associated with appreciable morbidity, particularly among workers in rubber plantations. ${ }^{12}$ Occasionally, loiasis occurs in non-tropical countries in people who have been iiving in regions in which it is endemic. The major clinical manifestations of the disease, produced by the adult parasites (the macrofilarias; migrating, through tissue, are transient, erratic itching subcutaneous swellings-the so called Calabar swellings-and conjunctivitis related tc the passage of the worm in the subconjunctival tissue. ${ }^{2}$ The microfilarias, the larvas laid. by the mature adult female, are usually not pathogenic but may become so and give rise to symptoms as the result of their massive lysis, ${ }^{12}$ when treatment is started with diethylcarbamazine, which has strong microfilaricidal and macrofilaricidai action against Loa loa.

Fever, headache, malaise, nausea, vomiting, arthralgias, increased swellings, and itching are common side effects of anti-

Blood Transfusion Centre Antwerp, B-2520 Edegem, Belgium LUDO MUYLLE, MD, deputy medical director ROBERT MOLDENHAUER, MD, general practitioner

Institute for Tropical Medicine, B-2000 Antwerp, Belgium HENRI TAELMAN, MD, DTM \& $\mathrm{H}$, associate chief of clinic ROGER VAN BRABANT, technical engineer

University of Antwerp, University Hospital, 2520 Edegem, Belgium MARC E PEETERMANS, MD, professor of haematology filarial treatment ${ }^{2} 4$ and are sometimes so severe with diethylcarbamazine that administration of the drug has to be interrupted. The major drawback of treatment of loiasis, however, is the occurrence of disturbances of the central nervous system, particularly post-therapeutic encephalitis. ${ }^{5}{ }^{6}$ Even when diethylcarbamazine is administerec very cautiously together with antihistamines or corticosteroids, neurological complications should be expected in patients with a microfilariaemia of $50000 / \mathrm{m}$ : (roughly 1000 microfilarias in one thick blood film) or higher " 'but severe drug reactions may also occur at lower levels.

We report on two patients with loiasis in whom treatment with diethylcarbamazine had to be stopped because of major side effects. To reduce the microfilariaemia and permit treatment we developed a procedure to extract microfilarias from the blood: as microfilarias collect in the buffy coat on centrifugation we extracted this layer with a blooc cell separator.

\section{Patients and methods}

PATIENTS

Case 1 - The patient was a 32 year old man who had worked as an agricultural technician in northern Zaire (Gbadolite) since 1976 and had complained of Calabar swellings since 1978. Treatment with diethylcarbamazine had proved unsuccessful because severe side effects (fever, nausea, vomiting) had necessitated repeated interruption of the treatment. On admission he had no symptoms and physical examination was normal. Laboratory tests gave the following results: 9000 Loa loa microfilarias/ml blood (Knott's method), total eosinophil count $54 \mathrm{C} \times 10^{6} / 1$, and IgE concentration $5000 \mathrm{U} / \mathrm{ml}$ (normal $\leqslant 122 \mathrm{U} /$ $\mathrm{ml}$ ). Results of serological examination were strongly positive for Filaria by enzyme linked immunosorbent assay. Because of the side effects of diethylcarbamazine in this patient three apheresis sessions to extract microfilarias were performed. Diethylcarbamazine was started afterwards beginning with a dose of $12.5 \mathrm{mg}$ and slowly increasing to $6 \mathrm{mg} / \mathrm{kg} /$ day after one week. This dosage was maintained for three weeks. Prednisolone was added to the treatment, initially at a dose of $15 \mathrm{mg} /$ day, but was tapered to zero when the full dose of diethylcarbamazine was reached.

Case 2-The patient was a 53 year old man who had worked as a missionary for 17 years in north eastern Zaire (Isiro), where loiasis is endemic. For several years he had had Calabar swellings. Several attempts at treatment with diethylcarbamazine, although starting with low doses, had had to be interrupted because of serious general side effects-namely, high fever, malaise, myalgias. On admission he was asymptomatic and physical examination was unremarkable. Laboratory investigations showed: 3750 Loa loa microfilarias $/ \mathrm{ml}$ blood (Knott's method), total eosinophil count $93 \times 10^{6} / 1$, and IgE concentration $350 \mathrm{U} / \mathrm{ml}$. Results of serological examination were strongly 